EPiC Series in Education Science
Volume 3, 2020, Pages 27-34
Proceedings of the MIT LINC 2019 Conference

\title{
Real and Virtual Biological Science Living Laboratory for Science Teachers' formation: promoting global scientific literacy and critical thinking for sustainable development.
}

María E. Castelló $^{*}$, Virginia E. Pellegrino ${ }^{2}$, Daniel A. Argente ${ }^{3}$, Jose Gomez-Marquez ${ }^{4}$, Urs Gaudenz ${ }^{5}$, Gregory Randall ${ }^{6}$, Ana C. Pereira ${ }^{2}$, Sandra

Alonso $^{2}$, Javier Calvelo ${ }^{1}$, Anne Young ${ }^{4}$, Fernando N. Acosta ${ }^{2}$, Nikolas Albarran ${ }^{4}$, Marcos I. Gimenez ${ }^{3}$, Pablo M. Sedraschi ${ }^{3}$, Marcos D. Umpiérrez ${ }^{3}$, Martin Figares ${ }^{1}$, Maria I. Rehermann de Sagastizabal ${ }^{1}$ and Milka D. Radmilovich $^{7}$

${ }^{1}$ Instituto de Investigaciones Biológicas Clemente Estable (MEC), Montevideo, Uruguay

${ }^{2}$ Consejo de Formación en Educación (ANEP), Montevideo, Uruguay

${ }^{3}$ Instituto Escuela Nacional de Bellas Artes (UdelaR), Montevideo, Uruguay

${ }^{4}$ Little Devices Lab (MIT), Cambridge MA, USA

${ }^{5}$ GaudiLabs, Lucerne, Switzerland

${ }^{6} \mathrm{Facultad}$ de Ingeniería (UdelaR), Montevideo, Uruguay

${ }^{7}$ Facultad de Medicina (UdelaR), Montevideo, Uruguay

mcastello@iibce.edu.uy, virginia.pellegrino@gmail.com, danielargente@gmail.com,

jfgm@mit.edu, urs@gaudi.ch, randall@fing.edu.uy, carolinapereiralarronde@gmail.com, salonsoamaya@gmail.com, javiercalvelo7@gmail.com, akyoung@mit.edu, feraco92@.gmail.com, nalbarra@mit.edu, 0000marcosg@gmail.com, pablosed@gmail.com, mumpierrez@,gmail.com, mfigares@,fcien.edu.uy, mirehermann@gmail.com, milka.radmilovich@gmail.com

\begin{abstract}
Global attempts to renew scientific education aim to stop the decline of young people's interest in science and technology, and to promote the development of citizens' scientific literacy for sustainable development. Among other changes, these aims require the adaptation of K12 Biological Science Teacher's training to meet the new objectives.

Scientific literacy involves knowing science and how knowledge is developed and validated, recognizing the interactions between science, technology and society, that is, the nature of science

${ }^{*}$ María Castelló and created the first draft and stable version of this document
\end{abstract}


(NoS; a set of meta-scientific contents that encompass historical, epistemological and sociological aspects of science with great value for scientific education). It also involves grasping of cognitive skills underlying critical thinking (CT; a set of cognitive abilities, including self-regulation and metacognitive processes) and creative problem solving. Therefore, scientific literacy contributes to making informed decisions, facilitating the participation of citizens in situations and dilemmas of scientific tenor.

In addition, CT is closely related to the performance of educators in their professional work. Particularly, in the teaching of science, CT skills favour and enhance the learning of concepts and theories linked not only to science but also to the NoS.

Considering the current conditions of middle-higher K12 Biological Science Teachers' formation and classrooms' limitations in our country and the region, we propose a pilot project aiming to promote the transformation of initial teachers' training, seeking to improve the development of CT skills and to deepen NoS comprehension. It will involve the immersion of K12 Biological Science Teacher students in Biological Science Living Physical and "mirror" Virtual Reality Laboratories. These laboratories will be equipped with "do it yourself" (DIY), "do it with others" (DIWO) and "bring your own device" (BYOD) technologies for the implementation of research-type activities framed in the philosophy of the "fabrication laboratories". The virtual platform will also comprise a library with didactic resources under permissive licenses to ensure a broader impact.

Within these environments, K12 Biological Science Teacher students will engage in the creation of didactic units involving problem solving and knowledge building in parallel to deeper understanding of scientific processes. We also hope to promote the creativity and innovation of the participants, and the appropriation of DIY/DIWO/BYOD and virtual reality technologies as educational resources in the classroom and everyday life.

Thanks to the virtual environment, this approach would also allow to reach both National and International K12 Biological Science Teacher students and graduate Biological Science Teachers. Considering the universal access to the Internet and free access to educational platforms in several countries, we also hope to impact on the non-formal and informal Biological Science education and contribute to achieving quality education for all (Objective \# 4 of the Agenda for Sustainable Development 2030, UNESCO) beyond geographical and cultural barriers.

This pilot project will be implemented by an interinstitutional, multidisciplinary and international team. It will capitalize on confluent groups' previous experience and complementary strengths in Science didactics (particularly biology), engineering, arts, virtual reality, fabrication, as well as open hardware and open software culture.

The experimental approach corresponds to a quasi-experimental pre-test/post-test design with control groups, and formative and summative evaluation.

As a result of the implementation of this educational innovation we expect to contribute to the improvement of Biological Science Teachers students' CT skills and promote their active involvement in practical activities that should enhance their professional activity.

\section{Introduction}

For knowledge to support social justice it is required a change of the epistemic matrix (1), that can be achieved by reconciling the generation of knowledge and the "learning of the known" and by combining theory and practice in the learning process. This is in accordance with some of the objectives and guidelines of the Declaration of Quito on science, knowledge, technologies and the arts: to "generate knowledge and democratize its access, use and exploitation through new modalities promoting social appropriation of technologies, knowledge and science, through means such as libraries and open digital repositories (\#2); to create capacities, scientific vocation and culture of innovation among children and young people of the region, through the development and implementation of new 
methods of teaching science at all levels (\#8); and to guarantee gender and ethnic-racial equity in access to the science, technology and innovation system, and in the generation of knowledge (\#9)"(2). Also, this agrees with the "Report on world development 2018: Learning to make the promise of education a reality" that warns about the "learning crisis" (breaking the relationship between teaching and learning), indicates faults of teachers and inputs (textbooks and technologies) and suggests teachers' motivation as a solution (3).

Worldwide efforts aim to transform scientific education, stop the decline of youth interest in science and promote the development of citizens scientific culture. There is also an ongoing pedagogical renewal to promote students' active role and improve the teaching of science and technology. Accordingly, UNESCO proposes student-centered learning for sustainable future development (http://www.unesco.org/education/tlsf/), a paradigm shift that requires adequate initial and permanent teachers' training (4).

Since the beginning of the 19th century, teachers have made explicit their appraisal of practical activities in learning $(5,6)$. Despite conflicting views $(5,7,8)$, there is a consensus on the importance of practical work $(5,9)$. Different categories of practical activities (experiences, illustrative experiments, practical exercises, and research) allow the achievement of different educational objectives. Experiences allow the perceptive familiarization with the phenomena; practical exercises allow to learn practical and technical skills, and research offers the opportunity to solve problems, build knowledge and understand the processes of science $(10,11)$.

Unfortunately, in many countries worldwide, including Uruguay, the implementation of these types of activities within the framework of the courses of Science Teacher Training Programs is hampered by the lack of equipment. This affects teachers' initial training and impairs their professional performance. Alternatively, "Do it yourself" (DIY), "do it with others" (DIWO) and "bring your own device" (BYOD) technologies are appropriate for implementing research-type activities because those are affordable technologies that promote the development of critical thinking (CT) (12). Thus, we propose an innovation in Science Teacher initial formation by the implementation of a Biological Science Living Laboratory as the educational environment.

$\mathrm{CT}$ is a motivation-driven way of thinking, aimed at solving a problem or answering a question. It is an intellectually demanding, disciplined, plastic and trainable process. CT involves cognitive processes such as methods of logical inquiry, information literacy and processing skills (analysis, evaluation, inference and reflective judgment), self-analysis (metacognition) and self-regulation (1319).

Considering the above mentioned, we posed the following question: Does the involvement in the implementation of a real \& virtual Biological Science Living Laboratory impact on K12 Biological Science Teacher students?

We hypothesize that this innovation in K12 Biological Science Teachers' training would have a positive impact on their initial formation and future professional performance.

\section{Methodology}

To test this hypothesis, we propose to implement a Biological Science Living Laboratory within the framework of the Uruguayan Biological Science Teacher Training Program at the Consejo de Formación en Educación (CFE) of the Administración Nacional de Educación Pública (ANEP).

The target population will be groups of students in the K12 Biological Science Teacher Training Program, at the first and second year of the career, studying Cell Biology and Human Anatomy and Physiology, respectively. CFE Teachers of Teachers, belonging to the research group will be in charge of the students' groups. Complying with the regulations of the Comité de Ética de Investigación en Seres Humanos (CEIH) of Instituto de Investigaciones Biológicas Clemente Estable (IIBCE), the 
activities will be developed upon participants signature of an express consent of agreement, ensuring the preservation of data anonymity

\subsection{Experimental design}

We will work using a pre-test/post-test with control group quasi-experimental design. The evaluation will be both formative and summative (20).

For the pre-test diagnosis, questionnaires validated by the research group will be based on those developed in the parallel research project EDU2015-64642-R (MINECO / FEDER), and will be applied to assess critical thinking skills, including methods of logical inquiry, information literacy and processing skills (analysis, evaluation, inference and reflective judgment), self-analysis (metacognition) and self-regulation, and "soft" skills such as collaborative job skills, the ability to communicate and reflect on the value of practical work.

Considering the results of the pre-test diagnosis, face-to-face and virtual workshops will be planned and implemented. Through these activities the aforementioned knowledge and CT skills would be acquired or deepened, according to each student's initial performance. Some of the thematic contents that allow the interdisciplinary work will be taken as the axis of the workshops, involving various subjects as cell biology, biophysics and biochemistry.

Students' work will be guided by challenges as for example, the elaboration of experimental activities based on the resolution of problems, involving different types of practical activities (experiences, illustrative experiments, practical exercises, and, preferably, research activities) and/or developing new tools for the generation of open educational resources (OERs) for its wide accessibility through platforms (local, national and/or international).

Although Information and Communication Technologies (ICTs) should occupy a relevant place in teachers' training, and recent efforts of different institutions place ICTs in a relevant position in teachers' initial training, teachers and students do not always share this priority (21). Thus, knowledge and management of new technological contexts are some of the competences that future teachers should develop in their initial training to improve their implementation in teachers' professional activities. It should not be limited to the use of electronic devices that mediate the use of ICTs in the classroom but should be an integral part of the learning processes contributing to their formation. Within this framework, and bearing in mind the experimental nature of biology, we propose the inclusion of ICTs in the creation of the Biological Science Virtual Living Laboratory.

At the end of the pilot project, a post-test evaluation (formative evaluation methodology based on self-evaluation and peer evaluation) and individual summative evaluation $(4,22)$ will be carried out to determine if the educational objectives of the project were achieved.

\subsection{Physical laboratory}

Considering the international antecedents previously mentioned, and the limitations experienced in the teaching and learning of Biological Sciences in Uruguayan education system, we propose the creation of a Biological Science Living Laboratory at the CFE (ANEP). Living laboratories consist of a structure made up of people -the key component- and technologies. These environments allow the participants (in particular Biological Science K12 Teacher students as well as K12 Biological Science Professors of Teachers) to be actively engaged in a research process that promotes creativity and 
multidisciplinarity. Inspired on the work philosophy of laboratories as Little Devices, GaudiLabs and Solution Space, the Biological Science Living Laboratory at CFE (ANEP) will be equipped with DIY/DIWO/BYOD-type technologies, that is with tools and instruments to manufacture equipment of low and high technology. Thus, it would avoid the need for significant investment regarding classical laboratory instrumentation (usually machines with closed architecture, expensive components, and private operation protocols) as they would hinder the direct "hands on" experimentation of the participants. The type and characteristics of the equipment of the Biological Science Living Laboratory at CFE (ANEP) will be selected by the Biological Science K12 Teacher students, according to the appropriateness to address problems related to different subjects included on the agenda in Biology, Biomedicine and Biotechnology.

\subsection{Virtual laboratory}

A virtual platform will be implemented, consisting of the simulation of a physical laboratory in which visitors can carry out research activities and experiments, using an appropriate interface for such purposes. Activities carried out in the Biological Science Living Physical Laboratory will be replicated through this platform in a Biological Science Living Virtual Laboratory. Biological Science Teacher students will be provided with instructions and additional information on the objectives, elements and equipment involved in the experiments. Users will be able to navigate between different setups provided with the necessary devices for the corresponding experiments.

One of the objectives of this platform is to guarantee the experience of the experiments for all students, avoiding the physical limitations of the Biological Science Living Physical Laboratory. Thus, all students will be allowed to access the Biological Science Living Virtual Laboratory in an unlimited and simultaneous way. Another striking feature of the Biological Science Living Virtual Laboratory is that Biological Science Teacher students will also have the opportunity to freely explore the possibilities of such experiments in a virtual and safe environment.

The complexity of the interaction will depend on the number of possible options within the experiments, that is, the number of steps that the procedure has and the variations or the order of these steps that would create a tree of possible outcomes. In addition, there will be a DIY construction simulator of suitable devices for carrying out the novel experiments in the laboratory.

To ensure that the largest possible number of students can access this platform, it will be presented in different formats for different devices, including mobile devices, desktops and an online version for web browsers.

The platform will have a link section to education and science resources, as well as international websites on DIY/DIWO/BYOD technologies for the construction of scientific instruments $(23,24)$, and access to web sites of laboratories and organizations.

A community section will be also built with a blog to promote the dissemination of the project and its progress, as well as interchange of experiences of Biological Science Teachers of Teachers, Biological Science Teachers and Students of the in person and of the semi-virtual the Biological Science Teacher Training Program.

\section{Expected results}

We expect the improvement in CT skills of Biological Science teachers students. Another of the expected results in the short term is the active involvement of Biological Science Teacher students in the practical activities. If this is achieved, it would be expected that when these students become teachers, they will be prone to incorporate problem solving as one of the educational strategies in the 
classroom, according to the Primary School Teacher Clemente Estable: "The educational task is learning to learn ... and one of the most important missions of the teaching is teaching to learn "(25).

To ensure a broader reach of the research, several activities will be implemented for the dissemination/extension of the results of the project to other Biological Science students and teachers, such as workshops and courses at several Teachers Formation Centers in different places in the country. This would enable the promotion of technologies and educational resources produced along the project to a broader population of Biological Science Teachers for its appropriation as didactic tools. Also, workshops for the general public would allow the extension of the experience and diffusion of the results to the community.

If a positive impact is achieved, it will be proposed to extend the experience to other Teacher Training Centers of classroom-based and semi-presential mode courses.

Due to the nature of the proposal, the theme and the proposed objectives, we believe that joint efforts of interdisciplinary and inter-institutional research groups is mandatory for the success of the proposal and mutual enrichment of members of the research group. Particularly, as in the case of our group, the mutual enrichment of Teachers of Teachers -with proficiency in disciplinary and didactic aspects of Biology teaching and learning process, and in the elaboration and digitalization of educational resources-, research scientists, particularly neuroscientists -with knowledge of the neurobiological basis of learning a teaching process-, artists and engineers -with expertise in virtual reality, robotics and fabrication laboratories-, is an added value.

It is also desirable the connection and collaboration with international groups with expertise in DIY/DIWO/BYOD that can share the "state of the art" as well as historical background of open hardware and open software philosophy. In our case, this will be achieved by the involvement of Little Devices Lab (MIT) Cambridge, MA, USA), GaudiLabs (Lucerne, Switzerland) and SDG Solution Space (Genève, Switzerland).

MIT Little Devices Lab explores the design, invention and feasibility of applying DIY technologies to health. They develop empowerment technologies for health that can be applied in the first line of medical care, including Ampli diagnostic blocks. GaudiLabs, belongs to the open source network hackteria.org integrated by creative and interdisciplinary spaces for research and development of methods, processes and devices to unite people and knowledge. GaudiLabs consists of a physical laboratory (Lucerne, Switzerland) and GaudiLabs mobile (to create temporary laboratory spaces). SDG Solution Space, within the Biotech Campus (Geneva), has its own Fabrication Laboratory with standard equipment suitable for promoting creative and critical thinking.

We expect that these collaborations should contribute to ensure the innovative character of the proposed project as well as potentiate the feasibility of its global implementation.

\section{References}

[1] CRES 2018, U. (2018). Declaración de la III Conferencia Regional de Educación Superior para América Latina y el Caribe. Integración y Conocimiento, 7(2), 96-105. Retrieved from https://revistas.unc.edu.ar/index.php/integracionyconocimiento/article/view/22610I

[2] ESALC, I. I. para la E. S. en A. L. y el C., \& UNESCO, O. de las N. U. para la E. la C. y la C. Declaración de Quito sobre la ciencia, los conocimientos, las tecnologías y las artes, Documento Propositivo: Los nuevos conocimientos emancipatorios desde el Sur $\S$ (2017). Quito, Ecuador. Retrieved from

[3] http://observasur.org/wp-content/uploads/2017/11/I-Declaraci\%C3\%B3n-Quito-sobreconocimientos-del-sur-rev-20-11-17-con-caratula-blanca.pdf

[4] Banco Mundial. (2017). El Banco Mundial advierte sobre una "crisis del aprendizaje" en la educación a nivel mundial. BancoMundial.Org. Retrieved from 
http://www.bancomundial.org/es/news/press-release/2017/09/26/world-bank-warns-of-learning-crisisin-global-education

[5] W. Harlen \& J.E. Allende. Teacher Professional Development in Pre-Secondary School InquiryBased Science Education (IBSE). GraficAndes, Santiago Chile, 2009.

[6] D. Hodson Hacia un enfoque más crítico del trabajo de laboratorio. (1994). Enseñanza de Las Ciencias: Revista de Investigación y Experiencias Didácticas, 12(3), 299-313.

[7] V. N. Lunetta, A. Hofstein, \& M. P. Clough Learning and teaching in the school science laboratory: an analysis of research, theory and practice. In: Abell, S. \& Lederman, N. (Eds.) Hanbook of research on science education (pp. 393-441). Lawrence Erlbaum Associates, New Jersey EEUU, 2007.

[8] Hofstein, A., \& Lunetta, V. N. (1982). The Role of the Laboratory in Science Teaching: Neglected Aspects of Research. Review of Educational Research, 52(2), 201-217.

[9] Reverdito A. M. \& Lorenzo, M.G. (2007) Actividades experimentales simples. Un punto de partida posible para la enseñanza de la química. Educación en la Química, 13(2):108-121.

[10] A. M. López Rua, \& Ó. E. Tamayo Alzate, Las prácticas de laboratorio en la enseñanza de las ciencias naturales. (2012). Revista Latinoamericana de Estudios Educativos (Colombia), 8(1), 145-166.

[11] Caamaño, A., \& Oñorbe, A. (2004). La enseñanza de la química: conceptos y teorías, dificultades de aprendizaje y replanteamientos curriculares. Alambique. Didáctica de Las Ciencias Experimentales, (41), 68-81.

[12] Mainardi \& Sztrajman. De la Pedagogía por Proyectos a la Estrategia de Proyectos: Continuidad y Cambio. En: Gómez Gallindo, A. A. y Quintanilla Gatica, M (Eds.) La enseñanza de las ciencias naturales basada en proyecto. Santiago de Chile, Chile, 2015.

[13] Meinardi, E. \& Sztrajman, J. (2015). De la pedagogía por proyectos a la estrategia de proyectos: continuidad y cambio. In A. Gómez, \& M. Quintanilla (Eds). Enseñanza de las Ciencias Naturales Basada en Proyectos. Santiago de Chile, Bella Terra Ltda.

[14] Bowler, L. \& Champagne, R. (2016). Mindful makers: Question prompts to help guide young peoples' critical technical practices in maker spaces in libraries, museums, and community-based youth organizations. Library and Information Science Research, 38(2), 117-124. https://doi.org/10.1016/j.lisr.2016.04.006

[15] Bailin, S., Case, R., Coombs, J. R., \& Daniels, L. B. (1999). Conceptualizing critical thinking. Journal of Curriculum Studies, 31(3), 285-302. https://doi.org/10.1080/002202799183133

[16] J. Dewey. How we think. Chapter 2 The Problem of Training Thought? D.C. Heath \& Co. $\begin{array}{llllll}\text { Boston New } & \text { York } & \text { Chicago } & \text { 1910. } & \text { Retreived }\end{array}$ https://archive.org/details/howwethink000838mbp/page/n7

[17] Dwyer, C. P., Hogan, M. J., \& Stewart, I. (2014). An integrated critical thinking framework for the 21st century. Thinking Skills and Creativity, 12, 43-52. https://doi.org/10.1016/j.tsc.2013.12.004

[18] Facione, P. A. (1990). Critical Thinking: A Statement of Expert Consensus for Purposes of Educational Assessment and Instruction Executive Summary " The Delphi Report. The California Academic Press, 423(c), 1-19. https://doi.org/10.1016/j.tsc.2009.07.002

[19] Siegel, H. (1985). Educating Reason: Critical Thinking, Informal logic, and the Philosophy of Education. Informal Logic, 7(2). https://doi.org/10.22329/il.v7i2.2706

[20] Cruz, S. (2008). Habilidades de pensamiento y aprendizaje profundo 1. Revista Iberoamericana de Educación, 1-9.

[21] Fisher, A. (2001). Critical Thinking. An Introduction. Library, 44(13), 17. https://doi.org/10.2307/2019787

[22] Echevarría, H.D. Los diseños de investigación cuantitativa en Psicología y educación. 1st ed. 2016 Río Cuarto, UniRío.

[23] Báez, A.R., Bañuls, M., Behrendt, G., García, A., Lugo, J. \& M; Tiramonti, G. Aportes para (re)pensar el vínculo entre Educación y TIC en la región. FLACSO Uruguay, 2013, pp.103-117.

[24] Rosales, M. M. (2014). Proceso evaluativo: evaluación sumativa, evaluación formativa y 
Assesment su impacto en la educación actual. Congreso Iberoamericano de Ciencia, Tecnología, Innovación y Educación, 1-13. Retrieved from http://www.oei.es/congreso2014/memoriactei/662.pdf

[25] Hsieh, T. H., Tsai, Y. C., Kao, C. J., Chang, Y. M., \& Lu, Y. W. (2014). A conceptual atomic force microscope using LEGO for nanoscience education. International Journal of Automation and Smart Technology, 4(2), 113-121. https://doi.org/10.5875/ausmt.v4i2.358

[26] Sharkey, J. P., Foo, D. C. W., Kabla, A., Baumberg, J. J., \& Bowman, R. W. (2016). A onepiece 3D printed flexure translation stage for open-source microscopy. Review of Scientific Instruments, 87(2). https://doi.org/10.1063/1.4941068

[27] C. Estable, Psicología de las vocaciones, Fundación Clemente Estable, Montevideo, Uruguay, 2003.

\section{Funding}

This work is supported by Agencia Nacional de Investigación e Innovación (Research Grant \#FSED_2_2018_1_150716)

\section{Acknowledgements}

The authors thank Dr. Catherine E. Carr for her diligent proof reading of the final version of this manuscript. The authors also thank 